\title{
The Effect of Recreational Physical Activity Training on Bio-motor Characteristics of Secondary School Students
}

\author{
Abdullah Güllü̈ ${ }^{1}$ Esin Güllü̈ ${ }^{1}$ \\ ${ }^{1}$ Abdullah Güllü, Hitit Üniversitesi, Turkey \\ Correspondence: Abdullah Güllü, Hitit Üniversitesi, Turkey. \\ Received: November 21, 2018 \\ Accepted: December 24, 2018 \\ Online Published: December 29, 2018 \\ doi:10.11114/jets.v7i1.3781 \\ URL: https://doi.org/10.11114/jets.v7i1.3781
}

\begin{abstract}
The aim of this study was to investigate the effect of recreational physical activity training on biomotor characteristics of 12-age group secondary school students. A total of 116 physically inactive male students in secondary school participated in this study as healthy and volunteer. Participants were divided randomly into three groups: the recreational soccer training group (SG; $\mathrm{n}$ : 43 ; height: $146.51 \pm 9.01 \mathrm{~cm}$; weight: $37.73 \pm 12.20 \mathrm{~kg}$ ), the recreational volleyball training group (VG; n: 37; height: $146.97 \pm 7.19 \mathrm{~cm}$; weight: $42.04 \pm 11.39 \mathrm{~kg}$ ) and the control group (CG; $\mathrm{n}$ : 36; height: $141.53 \pm 8.27 \mathrm{~cm}$; weight: $39.62 \pm 11.72 \mathrm{~kg}$ ). SG and VG completed their recreational physical activities in 2 days a week for 24 weeks. The body composition, speed, agility, flexibility, strength, anaerobic power and aerobic power values were measured. The paired-samples t-test and one-way ANOVA with multiple comparisons were used for evaluations of the groups. The level of significance was used at 0.05 . The results of the body composition and bio-motor capacities were significantly higher in favor of SG and VG than CG. In conclusion, recreational soccer and volleyball trainings may be proposed as entertaining physical activities that stimulate both body composition and bio-motor capacities.
\end{abstract}

Keywords: bio-motor capacity, body composition, recreational physical activity, soccer, secondary education, volleyball

\section{Introduction}

Participations in physical activities on a regular basis during adolescence cause significant changes that may positively affect growth and development. It is very important to know the bio-motor levels of the 12 year-old children in adolescence. Therefore, to have knowledge about physical, anthropometric and motoric responses of children to exercises, it is very important to understand the physiological benefits and potential risks of participation in sports activities on a regular basis (Gullu, 2013). Today, in spite of the increasing attendance of children at early ages to sports organizations (Adam \& Baxter-Jones, 1995), it is stated that many problems that occur during childhood and adolescence are caused by inadequate exercise habits and poor living standards (Astrand, 1977). In addition, physical inactivity is a global public health problem that contributes to the increasing prevalence of obesity, diabetes mellitus, cardiovascular disease, hypertension and stroke especially in modern societies (Lee \& Skerrett, 2001). Physically inactive children are at risk of suffering from mental problems and physical illnesses. Therefore, participation in physical activities is of paramount importance for the benefits of mental health and also for prevention of mental disorders (Sarmento, 2015). Recent studies show that many adolescents and children do not reach the recommended level of physical activity to reduce the risk of cardiovascular disease and physiological disorders (Hammami, Randers \& Kasmi, 2018). Studies investigating health-related physical fitness benefits have focused on aerobic exercises such as treadmills, open-air runs or bicycle ergometer on a regular basis in participating to physical activity (Duvivier et all., 2013). However, adherence to the types of physical activity, such as continuous running, is relatively low, especially in adolescents, because such activities are perceived as isolating and boring (Bartlett, Close, MacLaren, Gregson, Drust \& Morton, 2011). Therefore, although traditional programs such as treadmills and cycling ergometers provide us with important health benefits, effective physical activity programs are needed that better adapt (McKenzie, Cohen, Sehgal, Williamson \& Golinelli, 2006) and increase intrinsic motivation (Hammami et all., 2018). Positive changes in body composition are achieved not only by intensive energy expenditure during typical training sessions, but also by increased fat metabolism after activity (Hammami et all., 2016). Besides that, exercise performance improves together growth and biological maturity, which determines many physiological components (Adam \& Baxter-Jones 1995). Therefore, there is a need for more adaptive, more addictive and more enjoyable training methods that will optimize 
intrinsic motivation (Hammami et all., 2016; Helge et all., 2010). In this context, the importance of activities such as soccer (Helge et all., 2010; Saccol, Almeida \& de Souza, 2016) and volleyball (Saccol et all., 2016) increased. Because team sports for young people like soccer and volleyball are really fun and more than just an ordinary activity (Castagna, Sousa, Krustrup \& Kirkendall, 2018).

The purpose of this investigation is to evaluate the effects of recreational soccer and volleyball trainings which are applied regularly for six months to the male students in the 12-year age group of secondary education, with a current approach.

\section{Methods}

\subsection{Research Group}

Totally 116 male students, who were healthy and sedentary in the age group of 12 years in secondary school, participated in this study voluntarily. The study included healthy sedentary male students with no acute or chronic disease, who did not use any drugs or cigarettes, and who has not participated in any physical activity training group on a regular basis for at least 2 years. A total of 116 participants in the age group of 12 were randomly divided into three groups: a recreational soccer training group (SG; n: 43; height: $146.51 \pm 9.01 \mathrm{~cm}$; weight: $37.73 \pm 12.20 \mathrm{~kg}$ ), a recreational volleyball training group (VG; $\mathrm{n}$ : 37 ; height: $146.97 \pm 7.19 \mathrm{~cm}$; weight: $42.04 \pm 11.39 \mathrm{~kg}$ ) and a control group (CG; n: 36 ; height: $141.53 \pm 8.27 \mathrm{~cm}$; weight: $39.62 \pm 11.72 \mathrm{~kg}$ ) that did not participate in any physical activity on a regular basis. After that, the groups completed the recreational training activities on the same days and hours in different fields according to their branches. All tests performed before (pre-test) and after (post-test) the recreational soccer and volleyball training activities for 6 months ( 24 weeks), were completed in the same order. Before receiving written approval, the experimental protocols and related risks of the study were explained and announced in writing and verbally to all intervention groups and their families. Then, "the student/parent information form" and "the student/parent consent form" which were prepared according to the rules in the Helsinki Declaration, were signed for each participant. In addition, before starting the study, the health report approval which were "there is no objection to participate in the recreational soccer or volleyball training activities and tests", was taken from the hospital.

\subsection{Testing Measurements}

Body Composition: The height of the study group was measured in $\mathrm{cm}$ by the Harpenden stadiometer (Holtain, UK) in an upright position and bare feet. Body composition measurement was measured by bioelectric impedance analysis (Tanita BC-418 MA Professional, Japan) method for body weight, basal metabolism rate (BMR), body fat percentage $(\mathrm{BF} \%)$ and body fat mass (BFM), while the subjects were in shorts, t-shirt and bare feet. Body mass index (BMI) was calculated using the formula of $\left(\mathrm{kg} / \mathrm{m}^{2}\right)$.

Speed (S) Test: $30 \mathrm{~m}$ speed measurements were made with photocells (Katis \& Kellis, 2009).

Agility (A) Test: The Illinois agility test protocol was applied to agility measurements (Katis \& Kellis, 2009).

Flexibility (F) Test: Sit and reach tester was used for flexibility measurement (Erikoğlu, Güzel, Pense \& Örer 2015).

Strength Test: Handgrip strength (HGS) test was measured using a digital hand dynamometer (TKK 5401 Grip-D, Takei Scientific. Instruments Co. Ltd., Tokyo, Japan) (Yi, Khang, Lee, Son \& Kang, Y., 2018). Absolute HGS (AbS) was calculated with the sum of both (right and left) hand grip strengths and then, the Relative HGS (RelS) value of each subject was calculated by: Absolute HGS value dividing by BMI (Lee, Peng, Chiou \& Chen, 2016).

Anaerobic Power (AnP) Test: Sargent vertical jump (VJ) test was used to calculate the anaerobic power. The AnP of each participant was calculated by using the formula of $[\mathrm{AnP}(\mathrm{kgm} / \mathrm{s})=\sqrt{ } 4.9$ (Body weight) $\sqrt{ } \mathrm{D}, \mathrm{D}=$ the vertical jump distance (m)] (Katis \& Kellis, 2009).

Aerobic Power $\left(\mathrm{VO}_{2} \mathrm{max}\right)$ Test: In order to calculate the $\mathrm{VO}_{2} \mathrm{max}$, the Bruce test protocol was performed in a laboratory environment and on a computer controlled treadmill (Cosmed T-150, Italy). For this, each subject started with a 5 min warm-up run at $0 \%$ inclination and then the loaded protocol on the treadmill started automatically. Heart rate (HR) control was performed with the formula of [95\% x 220 beats/min - age] (Fredriksen, Ingjer, Nystad \& Thaulow, 1998), and it was checked with the portable pulse rate monitor (Polar S800i, Finland) during testing. The test was terminated according to the criteria of exhaustion (voluntary fatigue) against a specific workload, and Borg scale (Borg, 1982). End of test completion level, duration and $\mathrm{HR}$ values were recorded for each subject. The $\mathrm{VO}_{2}$ max capacities of the test groups were calculated according to the formula of $\left[\mathrm{VO}_{2} \max (\mathrm{mL} / \mathrm{kg} / \mathrm{min})=4.38 \times\right.$ Time $\left.(\mathrm{min})-3.9\right]$ (Mackenzie, 2005).

\subsection{Recreational Physical Training Programs}

Recreational soccer training programs were applied in synthetic grass surface soccer field, and volleyball training programs were conducted in the indoor sports hall with plastic rubber surface. The training sessions of each group were 
performed by two expert trainers with more than 3 years of experience. Soccer and volleyball training sessions in the form of recreational games were conducted for 6 months (24 wks.), and 2 days on weekends (Saturday and Sunday) for a total of one hour (between 09.00 and $10.00 \mathrm{am}$ ). At soccer physical training sessions, all of the match games were played without considering the player's position and no changes were made to the general rules of soccer. In all studies, number 4 soccer balls (Molten VG 121, USA), which were designed for children aged between 08-12 years and approved by FIFA, were used. At volleyball physical training sessions, all of the match games were played without considering the player's position and no changes were made to the general rules of volleyball. In all studies, number 5 mini volleyball balls (Mikasa SKV5 Kids, Japan), which were designed for children and approved by TVF, were used.

Table 1. Recreational soccer and volleyball daily training program ${ }^{\#}$

\begin{tabular}{|c|c|c|c|}
\hline Content & $\begin{array}{l}\text { Time } \\
(\text { min) }\end{array}$ & Soccer Group (SG) & Volleyball Group (VG) \\
\hline \multirow{2}{*}{ Warm-up } & 6 & $\begin{array}{l}\text { Dribbling and pass exercises with ball in different } \\
\text { directions in jogging tempos }\end{array}$ & $\begin{array}{l}\text { Overhead and forearm passes, and service } \\
\text { exercises in different directions }\end{array}$ \\
\hline & 4 & $\begin{array}{l}\text { Ballistic and short-term static stretching movements of } \\
\text { arm and leg muscles }\end{array}$ & $\begin{array}{l}\text { Ballistic and short-term static stretching } \\
\text { movements of arm and leg muscles }\end{array}$ \\
\hline $\begin{array}{l}\text { Type of } \\
\text { training }\end{array}$ & $5+2$ & $\begin{array}{l}\text { Different ball exercises (e.g.: ball control, passing, } \\
\text { shooting, quick dribbling types; different coordination } \\
\text { exercises with and without the ball) and a total of } 2 \\
\text { minutes passive rest between them. }\end{array}$ & $\begin{array}{l}\text { Different ball exercises (e.g.: pass, service, } \\
\text { spike and block types etc.; defensive and } \\
\text { offensive exercises)and a total of } 2 \text { minutes } \\
\text { passive rest between them. }\end{array}$ \\
\hline Match game & 35 & $\begin{array}{l}\text { 1st half: } 6 \times 6 \text { matched match game, }(15 \mathrm{~min}) \\
\text { Half time, }(5 \mathrm{~min}) \\
\text { 2nd half: } 6 \times 6 \text { matched match game, }(15 \mathrm{~min})\end{array}$ & $\begin{array}{l}\text { 1st set: Match game, (15 points) } \\
\text { Break, ( } 2 \text { min) } \\
\text { 2nd set: Match game, (15 points) } \\
\text { Break, ( } 2 \text { min }) \\
\text { 3rd set: Match game. (15 points) }\end{array}$ \\
\hline \multirow[b]{2}{*}{ Cool-down } & 3 & Active recovery method: jogging & Active recovery method: jogging \\
\hline & 5 & $\begin{array}{l}\text { Passive recovery method: static stretching exercises for } \\
\text { working muscles }\end{array}$ & $\begin{array}{l}\text { Passive recovery method: static stretching } \\
\text { exercises for working muscles }\end{array}$ \\
\hline
\end{tabular}

${ }^{\#}$ Frequency of physical activity: 2 days / week (Saturday and Sunday)

\section{Statistical Analysis}

Shapiro-Wilk test was used for the normality tests of all data. Since all of the data showed normal distribution ( $p>0.05$ ), parametric tests were performed. Intra-group differences were determined by paired samples t-test. The variances between the groups were determined by one-way ANOVA and Tukey HSD multiple comparison (post-hoc) tests. The statistical calculations of the study were done with IBM SPSS 25.0 statistics program, and $\mathrm{p}<0.05$ level was accepted as significant in all tests.

\section{Results}

The training programs in the form of recreational games (Table 1) were regularly applied to SG and VG for six months. Body composition and bio-motor capacity test values of the groups (SG, VG and CG) were taken before (pre-test) and after (post-test) the study and their effects on the groups were examined. Obtained pre- and post-tests values of the research group were compared statistically: (1) within-group comparisons, and (2) multiple comparisons between groups. In terms of baseline results, body composition and bio-motor capacity values of healthy male SG and VG had significantly higher performance compared to the CG, who had not received any physical activity training. The results were presented below in the Tables 2, 3 and 4 . 
Table 2. Descriptive values, and pre- and post-test comparisons of soccer group, volleyball group and control group

\begin{tabular}{|c|c|c|c|c|c|c|c|c|}
\hline \multirow[b]{2}{*}{ Variables } & \multirow[b]{2}{*}{ Group } & \multirow[b]{2}{*}{$\mathrm{N}$} & \multirow{2}{*}{$\begin{array}{c}\text { Pre-Test } \\
\mathrm{X} \pm \mathrm{SD}\end{array}$} & \multirow{2}{*}{$\begin{array}{c}\text { Post-Test } \\
\mathrm{X} \pm \mathrm{SD}\end{array}$} & \multicolumn{2}{|c|}{$\begin{array}{l}95 \% \text { Confidence } \\
\text { Interval of the } \\
\text { Difference }\end{array}$} & \multicolumn{2}{|c|}{$\begin{array}{l}\text { Paired samples } \\
\text { t-test }\end{array}$} \\
\hline & & & & & Lower & Upper & $\mathrm{t}$ & $p$ \\
\hline \multirow{4}{*}{ Stature $(\mathrm{cm})$} & SG & 43 & $146.51 \pm 9.01$ & $147.95 \pm 9.39$ & -1.61 & -1.27 & -17.26 & $0.000 *$ \\
\hline & VG & 37 & $146.97 \pm 7.19$ & $148.89 \pm 7.49$ & -2.08 & -1.75 & -23.67 & $0.000^{*}$ \\
\hline & $\mathrm{CG}$ & 36 & $141.53 \pm 8.27$ & $142.67 \pm 8,44$ & -5.65 & 2.68 & $-0 ., 73$ & 0.473 \\
\hline & SG & 43 & $37.73 \pm 12.20$ & $37.83 \pm 11.84$ & -0.37 & 0.17 & -0.73 & 0.468 \\
\hline \multirow{3}{*}{ Body mass $(\mathrm{kg})$} & VG & 37 & $42.04 \pm 11.39$ & $42.23 \pm 10.11$ & -0.73 & 0.35 & -0.72 & 0.478 \\
\hline & $\mathrm{CG}$ & 36 & $39.62 \pm 11.72$ & $40.58 \pm 11.17$ & -7.37 & 2.76 & -0.93 & 0.362 \\
\hline & SG & 43 & $17.10 \pm 3.49$ & $16.94 \pm 3.27$ & -0.1 & 0.43 & 1.22 & 0.228 \\
\hline \multirow{3}{*}{ BMI $\left(\mathrm{kg} / \mathrm{m}^{2}\right)$} & VG & 37 & $19.24 \pm 4.21$ & $18.91 \pm 3.47$ & 0.04 & 0.62 & 2.34 & $0.025^{*}$ \\
\hline & $\mathrm{CG}$ & 36 & $19.53 \pm 3.88$ & $19.69 \pm 3.54$ & -2.03 & 0.76 & -0.93 & 0.361 \\
\hline & SG & 43 & $1355.26 \pm 187.81$ & $1393.84 \pm 196.73$ & -55.58 & -21.58 & -4.58 & $0.000 *$ \\
\hline \multirow{3}{*}{ BMR (Kcal) } & VG & 37 & $1436.19 \pm 185.46$ & $1461.54 \pm 175.25$ & -33.39 & -17.31 & -6.4 & $0.000 *$ \\
\hline & $\mathrm{CG}$ & 36 & $1348.83 \pm 185.30$ & $1364.64 \pm 185.67$ & -114.38 & 43.75 & -0.91 & 0.370 \\
\hline & SG & 43 & $17.87 \pm 5.84$ & $16.65 \pm 4.93$ & $0 ., 64$ & 1.81 & 4.23 & $0.000^{*}$ \\
\hline \multirow{3}{*}{$\mathrm{BF} \%$} & VG & 37 & $19.91 \pm 6.72$ & $18.67 \pm 5.94$ & 0.87 & 1.61 & 6.82 & $0.000 *$ \\
\hline & CG & 36 & $24.41 \pm 5.89$ & $24.73 \pm 5.64$ & -3.18 & 1.33 & -0.83 & 0.41 \\
\hline & SG & 43 & $7.92 \pm 5.60$ & $6.75 \pm 3.94$ & 0.53 & 1.82 & 3.66 & $0.001 *$ \\
\hline \multirow[t]{3}{*}{ BFM (kg) } & VG & 37 & $8.69 \pm 5.07$ & $7.79 \pm 4.30$ & 0.62 & 1.19 & 6.48 & $0.000 *$ \\
\hline & CG & 36 & $10.18 \pm 5.36$ & $10.75 \pm 4.98$ & -3.29 & 0.77 & -1.26 & 0.217 \\
\hline & SG & 43 & $19.79 \pm 5.81$ & $21.79 \pm 6.01$ & -2.31 & -1.69 & -13.12 & $0.000 *$ \\
\hline \multirow[t]{3}{*}{$\mathrm{F}(\mathrm{cm})$} & VG & 37 & $20.51 \pm 5.23$ & $23.22 \pm 4.97$ & -3.01 & -2.4 & -18.09 & $0.000 *$ \\
\hline & $\mathrm{CG}$ & 36 & $18.00 \pm 5.50$ & $19.17 \pm 5.11$ & -3.83 & 1.71 & -0.78 & 0.443 \\
\hline & SG & 43 & $27.71 \pm 5.19$ & $28.54 \pm 4.97$ & -4.47 & -3.76 & -23.45 & $0.000 *$ \\
\hline \multirow[t]{3}{*}{$\mathrm{AbS}(\mathrm{kg})$} & VG & 37 & $29.21 \pm 6.54$ & $31.01 \pm 6.07$ & -7.83 & -6.76 & -27.72 & $0.000^{*}$ \\
\hline & $\mathrm{CG}$ & 36 & $28.18 \pm 7.76$ & $29.91 \pm 7.18$ & -3.07 & -2.46 & -18.33 & $0.000 *$ \\
\hline & SG & 43 & $0.19 \pm 0.04$ & $0.19 \pm 0.04$ & -0.31 & -0.24 & -14.44 & $0.000 *$ \\
\hline \multirow{3}{*}{ RelS } & VG & 37 & $0.20 \pm 0.04$ & $0.21 \pm 0.04$ & -0.45 & -0.38 & -25.1 & 0.000 * \\
\hline & $\mathrm{CG}$ & 36 & $0.20 \pm 0.05$ & $0.21 \pm 0.05$ & -0.17 & -0.08 & -6.05 & $0.000 *$ \\
\hline & SG & 43 & $43.57 \pm 12.13$ & $47.68 \pm 11.65$ & -4.74 & -3.49 & -13.28 & $0.000^{*}$ \\
\hline \multirow{3}{*}{$\mathrm{AnP}(\mathrm{kgm} / \mathrm{min})$} & VG & 37 & $45.03 \pm 7.61$ & $50.87 \pm 8.99$ & -6.92 & -4.77 & -11.03 & $0.000 *$ \\
\hline & $\mathrm{CG}$ & 36 & $37.41 \pm 9.95$ & $40.76 \pm 9.80$ & -4.01 & -2.69 & -10.37 & $0.000 *$ \\
\hline & SG & 43 & $21.65 \pm 1.77$ & $20.48 \pm 1.59$ & 0.92 & 1.41 & 9.51 & $0.000 *$ \\
\hline \multirow{3}{*}{$\mathrm{A}(\mathrm{sec})$} & VG & 37 & $21.99 \pm 2.05$ & $21.26 \pm 1.90$ & 0.55 & 0.92 & 7.91 & $0.000 *$ \\
\hline & CG & 36 & $21.70 \pm 1.70$ & $21.27 \pm 1.63$ & 0.3 & 0.54 & 7.26 & $0.000 *$ \\
\hline & SG & 43 & $6.08 \pm 0.51$ & $4.95 \pm 0.50$ & 0.99 & 1.26 & 17.22 & $0.000 *$ \\
\hline \multirow{2}{*}{$S(\mathrm{sec})$} & VG & 37 & $6.49 \pm 0.69$ & $6.25 \pm 0.67$ & 0.18 & 0.3 & 8.33 & $0.000 *$ \\
\hline & CG & 36 & $6.71 \pm 0.72$ & $6.44 \pm 0.68$ & 0.2 & 0.33 & 8.26 & $0.000^{*}$ \\
\hline \multirow{3}{*}{$\begin{array}{l}\mathrm{VO}_{2} \max \\
(\mathrm{mL} / \mathrm{kg} / \mathrm{min})\end{array}$} & SG & 43 & $42.13 \pm 4.25$ & $47.18 \pm 4.39$ & 0.99 & 1.26 & 17.22 & $0.000 *$ \\
\hline & VG & 37 & $40.45 \pm 6.81$ & $45.31 \pm 6.52$ & 14.78 & 106.21 & 2.68 & $0.011 *$ \\
\hline & $\mathrm{CG}$ & 36 & $39.04 \pm 3.09$ & $42.28 \pm 3.49$ & -3.49 & -2.99 & -26.19 & $0.000 *$ \\
\hline
\end{tabular}

Note. ${ }^{*} p<0.05 ; \mathrm{X} \pm \mathrm{SD}$ : mean and standard deviation; BMI: body mass index; BMR:basal metabolism rate; BF\%:body fat percentage; BFM: body fat mass; F: flexibility; AbS: absolute strength; RelS: relative strength; AnP: anaerobic power; A: agility; $\mathrm{S}$ : speed; $\mathrm{VO}_{2}$ max: aerobic power

Table 3. Pre- and post-test ANOVA results between soccer group, volleyball group and control group

\begin{tabular}{|c|c|c|c|c|c|c|c|c|}
\hline \multirow[b]{2}{*}{ Variables } & \multicolumn{4}{|c|}{ Pre-Test } & \multicolumn{4}{|c|}{ Post-Test } \\
\hline & $\begin{array}{c}\text { Sum of } \\
\text { Squares }\end{array}$ & $\begin{array}{l}\text { Mean } \\
\text { Square }\end{array}$ & $\mathrm{F}$ & $p$ & $\begin{array}{l}\text { Sum of } \\
\text { Squares }\end{array}$ & $\begin{array}{c}\text { Mean } \\
\text { Square }\end{array}$ & $\mathrm{F}$ & $p$ \\
\hline Stature $(\mathrm{cm})$ & 674.85 & 337.43 & 4.98 & $0.008^{*}$ & 830.07 & 415.03 & 5.71 & $0.004 *$ \\
\hline Body mass (kg) & 368.91 & 184.45 & 1.33 & 0.270 & 397.55 & 198.77 & 1.61 & 0.204 \\
\hline $\operatorname{BMI}\left(\mathrm{kg} / \mathrm{m}^{2}\right)$ & 141.96 & 70.98 & 4.79 & $0.010^{*}$ & 160.98 & 80.49 & 6.88 & $0.002 *$ \\
\hline BMR (Kcal) & 178015.4 & 89007.72 & 2.57 & 0.081 & 182067.7 & 91033.8 & 2.61 & 0.078 \\
\hline $\mathrm{BF} \%$ & 861.61 & 430.8 & 11.39 & $0.000^{*}$ & 1350.01 & 675.01 & 22.4 & $0.000 *$ \\
\hline BFM (kg) & 101.89 & 50.95 & 1.77 & 0.175 & 328.87 & 164.44 & 8.5 & $0.000 *$ \\
\hline $\mathrm{F}(\mathrm{cm})$ & 122.5 & 61.25 & 2.00 & 0.140 & 308.06 & 154.03 & 5.25 & $0.007 *$ \\
\hline $\mathrm{AbS}(\mathrm{kg})$ & 45.90 & 22.95 & 0.54 & 0.583 & 122.78 & 61.39 & 1.66 & 0.194 \\
\hline RelS & 0.07 & 0.04 & 0.65 & 0.524 & 0.09 & 0.04 & 1.93 & 0.150 \\
\hline $\mathrm{AnP}(\mathrm{kgm} / \mathrm{min})$ & 1200.82 & 600.41 & 5.79 & $0.004 *$ & 1951.66 & 975.83 & 9.21 & $0.000^{*}$ \\
\hline$A(\sec )$ & 2.59 & 1.29 & 0.38 & 0.683 & 16.36 & 8.18 & 2.82 & 0.064 \\
\hline$S(\mathrm{sec})$ & 8.19 & 4.09 & 9.91 & $0.000^{*}$ & 53.24 & 26.62 & 69.63 & $0.000 *$ \\
\hline $\mathrm{VO}_{2} \max (\mathrm{mL} / \mathrm{kg} / \mathrm{min})$ & 188.8 & 94.4 & 3.86 & $0.024 *$ & 475.49 & 237.74 & 9.71 & $0.000^{*}$ \\
\hline
\end{tabular}

Note. ${ }^{*} p<0.05$; BMI: body mass index; BMR: basal metabolism rate; BF\%: body fat percentage; BFM: body fat mass;

F: flexibility; AbS: absolute strength; RelS: relative strength; AnP: anaerobic power; A: agility; $\mathrm{S}$ : speed; $\mathrm{VO}_{2} \mathrm{max}$ aerobic power 
Table 4. Multiple comparison results of pre- and post-test between soccer group, volleyball group and control group

\begin{tabular}{|c|c|c|c|c|c|c|c|c|c|c|c|c|}
\hline \multirow[b]{3}{*}{ Variables } & \multicolumn{7}{|c|}{ Pre-Test } & \multicolumn{5}{|c|}{ Post-Test } \\
\hline & \multicolumn{2}{|c|}{ Group } & \multicolumn{5}{|c|}{ 95\% Confidence Interval } & \multirow[b]{2}{*}{$\mathrm{I}-\mathrm{J}$} & \multirow[b]{2}{*}{ SE } & \multirow[b]{2}{*}{$p$} & \multicolumn{2}{|c|}{$95 \%$ Confidence Interval } \\
\hline & I & $\mathrm{J}$ & $\mathrm{I}-\mathrm{J}$ & SE & $p$ & LB & UB & & & & LB & UB \\
\hline \multirow{2}{*}{ Stature $(\mathrm{cm})$} & \multirow{2}{*}{$\mathrm{CG}$} & SG & -4.99 & 1.86 & $0.02 *$ & -9.40 & -0.57 & -5.29 & 1.93 & $0.02 *$ & -9.86 & -0.71 \\
\hline & & VG & -5.45 & 1.93 & $0.02 *$ & -10.02 & -0.87 & -6.23 & 2.00 & $0.01 *$ & -10.97 & -1.48 \\
\hline \multirow{2}{*}{$\begin{array}{l}\text { Body mass } \\
(\mathrm{kg})\end{array}$} & \multirow{2}{*}{ CG } & SG & 1.88 & 2.67 & 0.76 & -4.45 & 8.22 & 2.75 & 2.51 & 0.52 & -3.21 & 8.71 \\
\hline & & VG & -2.42 & 2.76 & 0.66 & -8.98 & 4.14 & -1.65 & 2.60 & 0.80 & -7.83 & 4.52 \\
\hline \multirow{2}{*}{ BMI $\left(\mathrm{kg} / \mathrm{m}^{2}\right)$} & \multirow{2}{*}{ CG } & SG & 2.42 & 0.87 & $0.02 *$ & 0.36 & 4.49 & 2.75 & 0.77 & $0.00 *$ & 0.91 & 4.59 \\
\hline & & VG & 0.28 & 0.9 & 0.95 & -1.86 & 2.43 & 0.78 & 0.80 & 0.59 & -1.12 & 2.69 \\
\hline \multirow{2}{*}{ BMR (Kcal) } & \multirow{2}{*}{ CG } & SG & -6.42 & 42.08 & 0.99 & -106.37 & 93.53 & -29.2 & 42.17 & 0.77 & -129.35 & 70.96 \\
\hline & & VG & -87.36 & 43.61 & 0.12 & -190.93 & 16.22 & -96.9 & 43.70 & 0.07 & -200.69 & 6.89 \\
\hline \multirow{2}{*}{$\mathrm{BF} \%$} & \multirow{2}{*}{ CG } & SG & 6.54 & 1.39 & $0.00 *$ & 3.24 & 9.84 & 8.08 & 1.24 & $0.00 *$ & 5.14 & 11.03 \\
\hline & & VG & 4.51 & 1.44 & $0.01 *$ & 1.09 & 7.93 & 6.06 & 1.29 & $0.00 *$ & 3.01 & 9.11 \\
\hline \multirow{2}{*}{ BFM (kg) } & \multirow{2}{*}{ CG } & SG & 2.26 & 1.21 & 0.15 & -0.61 & 5.14 & 4.00 & 0.99 & $0.00 *$ & 1.64 & 6.36 \\
\hline & & VG & 1.49 & 1.26 & 0.47 & -1.49 & 4.47 & 2.96 & 1.03 & $0.01 *$ & 0.51 & 5.40 \\
\hline \multirow{2}{*}{$\mathrm{F}(\mathrm{cm})$} & \multirow{2}{*}{ CG } & SG & -1.79 & 1.25 & 0.33 & -4.76 & 1.18 & -3.02 & 1.22 & $0.02 *$ & -5.53 & 0.28 \\
\hline & & VG & -2.51 & $1 ., 3$ & 0.13 & -5.59 & 0.57 & -4.05 & 1.27 & $0.01 *$ & -7.06 & -1.04 \\
\hline \multirow{2}{*}{$\mathrm{AbS}(\mathrm{kg})$} & \multirow{2}{*}{ CG } & SG & 0,47 & 1,47 & 0,95 & $-3,02$ & 3,96 & 1,38 & 1,37 & 0,58 & $-1,88$ & 4,64 \\
\hline & & VG & -1.03 & 1.52 & 0.78 & -4.64 & 2.59 & -1.09 & 1.42 & 0.72 & -4.47 & 2.28 \\
\hline \multirow{2}{*}{ RelS } & \multirow{2}{*}{ CG } & SG & 0.01 & 0.01 & 0.58 & -0.01 & 0.03 & 0.02 & 0.01 & 0.18 & -0.01 & 0.04 \\
\hline & & VG & 0.00 & 0.01 & 1.00 & -0.02 & 0.02 & 0.00 & 0.01 & 0.97 & -0.02 & 0.03 \\
\hline \multirow{2}{*}{$\mathrm{AnP}(\mathrm{kgm} / \mathrm{min})$} & & SG & -6.16 & 2.30 & $0.02 *$ & -11.62 & -0.69 & -6.92 & 2.33 & $0.01 *$ & -12.44 & -1.40 \\
\hline & $C G$ & VG & -7.62 & 2.39 & $0.01 *$ & -13.28 & -1.95 & -10.11 & 2.41 & $0.00 *$ & -15.83 & -4.38 \\
\hline A & $C G$ & SG & 0.04 & 0.42 & 0.99 & -0.95 & 1.03 & 0.79 & 0.39 & 0.11 & -0.13 & 1.70 \\
\hline $\mathrm{A}(\mathrm{sec})$ & $\mathrm{Cu}$ & VG & -0.3 & 0.43 & 0.77 & -1.32 & 0.73 & 0.02 & 0.40 & 0.94 & -0.93 & 0.96 \\
\hline & & SG & 0.63 & 0.15 & $0.00 *$ & 0.29 & 0.98 & 1.49 & 0.14 & $0.00 *$ & 1.16 & 1.83 \\
\hline$S(\mathrm{sec})$ & $\mathrm{CG}$ & VG & 0.22 & 0.15 & 0.30 & -0.13 & 0.58 & 0.20 & 0.14 & 0.36 & -0.15 & 0.54 \\
\hline $\mathrm{VO}_{2} \max$ & $\mathrm{CG}$ & SG & -3.09 & 1.12 & $0.02 *$ & -5.74 & -0.44 & -4.91 & 1.12 & $0.00 *$ & -7.56 & -2.25 \\
\hline$(\mathrm{mL} / \mathrm{kg} / \mathrm{min})$ & $c G$ & VG & -1.41 & 1.16 & 0.44 & -4.16 & 1.34 & -3.04 & 1.16 & $0.03 *$ & -5.79 & -0.28 \\
\hline
\end{tabular}

Note. * $p<0.05$; SE: standard error; LB: lower bound; UP: upper bound; BMI: body mass index; BMR: basal metabolism rate; $\mathrm{BF} \%$ : body fat percentage; BFM: body fat mass; F: flexibility; AbS: absolute strength; RelS: relative strength; AnP: anaerobic power; A: agility; S: speed; VO2max: aerobic power

In this study, there were significant differences in body composition values within and between groups $(\mathrm{p}<0.05$; Table 2 , 3 and 4). It was observed that there was a positive effect on within-group flexibility in SG and VG, except CG, ( $<<0.05$; Table 2). But, according to post-hoc test values, significant improvements in flexibility were observed in favor of VG according to CG and SG ( $\mathrm{p}<0.05$; Table 4). Also, significant improvements were found intra-group absolute and relative HGS values of the three groups ( $<<0.05$; Table 2). For agility; significant improvements were found among the intra-group agility values of healthy male students in soccer and volleyball group ( $<<0.05$; Table 2). Significant improvements were found in intra-group speed values of healthy male students in SG and VG ( $<<0.05$; Table 2). But, in terms of speed values between groups, only improvement was observed in favor of VG ( $\mathrm{p}<0.05$; Tables 3 and 4 ). Also, significant differences were observed between the anaerobic power values in terms of intra-group comparisons ( $<<0.05$; Table 2) and in the between group comparisons, in favor of SG and VG ( $<<0.05$; Tables 3 and 4). Among the $\mathrm{VO}_{2} \max$ values of our study, significant improvements were found in favor of SG and VG, both in intra-group comparisons $(\mathrm{P}<0.05$; Table 2$)$, and in between group comparisons $(\mathrm{P}<0.05$; Tables 3 and 4$)$.

\section{Discussion}

Positive effects on the body composition of healthy male adolescents $(\mathrm{P}<0.05$; Table 2, 3 and 4$)$ can be caused by recreational training sessions applied for 24 weeks. The observed benefits include significant improvements in height, BMI, BMR and BF\% values can be said. Especially, the significant development in height can be thought to be caused by rapid development in arm and leg limbs during the puberty, which called "pubertal growth spurt" (Akçan, Tekgul, Karademirci \& Ongel, 1999). However, it can be said that, except CG, only significant improvements in height development of SG and VG were observed, and the recreational training sessions in game forms (Table 1), which were applied regularly during 24 weeks, contributed to this improvement. This increase in height may also be the cause of a significant difference in the BMI of SG and VG. In addition, the positive changes in BMR and BF\% may be attributed to intensive energy expenditure during the typical training sessions in the form of game, and also, not only in the activity period, but also in the increased fat metabolism after this training sessions. However, this difference may also be related to uncontrolled diet changes during these studies.

Since flexibility is one of the most important basic bio-motor features required in volleyball (Manshouri, Rahnama \& Khorzoghi, 2014), the fact that significant improvements in F capacity were observed in favor of VG according to other 
groups (Table 4). So, it is thought that volleyball education programs, which are regularly applied during 6 months, may have a positive effect on this capacity.

Hand grip strength represents the whole body strength and HGS is a simple, convenient and fast method to assess total muscle strength (Yi et all., 2018). Considering the effort time and the need for fast and correct playing during the soccer and volleyball match games, the necessity of basic motor characteristics such as strength in both branches is revealed. In addition, it is seen that compound motoric features such as speed of strength and endurance of strength are at the forefront in efforts to attack in both branches (Koc \& Aslan, 2010). For this reason, the efforts during the 6-month recreational soccer and volleyball training programs (Table 1) could have positively affected the strength components of SG and VG.

Although the positive developments in the A of SG and VG were not designed to improve performance of agility in recreational training programs (Table 1), it was remarkable. These developments in the ability of A may be due to the studies performed, as well as rapid perception, quick decision making and quick application skills (Lidor \& Ziv, 2010) during the match games.

Speed in sport, the person's motoric actions in the shortest period of time, refers to the most intensive application (Bilgic, Pancar, Sahin \& Ozdal, 2016). Due to the nature and rules of the volleyball branch, a certain level of muscle strength, agility and speed skills should be used frequently (Sheppard, Gabbett \& Riggs, 2013). For this reason, the efforts of VG to use these motoric features repeatedly during volleyball match games may have led to the development of $\mathrm{S}$ capacity in favor of VG.

Sufficient level of the anaerobic power in athletes is directly proportional to the ability to use the ATP-CP energy source (Bilgic et all., 2016). Well-developed anaerobic acidic (phosphocreatine) and anaerobic lactic (anaerobic glycolytic) energy systems are important for soccer (Gullu, 2011) and volleyball players (Sheppard et all., 2013). For this reason, as the soccer players (Haugen, Tønnessen \& Seiler, 2013) and volleyball players (Martinez, 2017; Radua, Făgăraş \& Graurc, 2015) use the VJ with intensity, improving this capacity can improve the performance of the game, because soccer and volleyball is characterized by short and frequent explosive activities such as jumping, hopping, turning and ball game. In addition, VJ, which is frequently used in volleyball, has the advantage of being sport specific (Martinez, 2017). Soccer and volleyball is a team sport that often uses these activities in a typical game. These also determine the basic performance levels of SG and VG. Therefore, it can be said that, the match games in both applied recreational training programs (Table 1) forced the SG and VG to use their anaerobic powers continuously and repetitively. So, these applications may explain the significant improvements in the AnP resulting in positive adaptations in favor of SG and VG.

In particular, evaluation of some performance parameters such as $\mathrm{VO}_{2} \mathrm{max}$ in team sports is of great importance in terms of monitoring and evaluation of training. As the $\mathrm{VO}_{2}$ max capacity is an important feature in soccer players (Erikoglu, Güzel, Pense \& Orer, 2015), volleyball players must also have a well-developed aerobic capacity (Sheppard et all., 2013). Therefore, SG and VG may have forced the use of repetitive frequency of $\mathrm{VO}_{2}$ max capacities in a certain level due to the content of the applied recreational training sessions (Table 1). Thus, as a result of the application of both types of recreational training, it may have caused an increase in fat oxidation (Rampinini et all., 2007), which in turn may led to intensive use of aerobic energy metabolism and, in turn, may have triggered developments in the aerobic power. These situations may be the reason for the significant improvements in $\mathrm{VO}_{2}$ max capacities, and positive adaptations resulting in favor of SG and VG.

\section{Conclusion}

It is concluded that there are types of training that produce positive physical and physiological responses on healthy individuals, regardless of age or physical activity experience in recreational soccer and volleyball. It was also concluded that recreational soccer and volleyball could be promising physical activities to overcome obstacles such as cost efficiency, time efficiency, and access to facilities and intrinsic motivation. These types of trainings may be proposed as complex physical activities of different movement patterns that stimulate both body composition and bio-motor performances. In addition, performance-related training methods such as recreational soccer and volleyball are a highly motivating and entertaining social activity that improves more fitness than traditional training protocols. For this reason, as the performance-related activities and because of their popularities, the recreational soccer and volleyball; they are ideal for eliminating the lack of physical activity and motivation and reinforcing social habits. Finally, future studies should compare the effects of the recreational soccer and volleyball training programs with other team sports and traditional training programs.

\section{References}

Adam, D., \& Baxter-Jones, G. (1995). Growth and development of young athletes. Sports Medicine. 2(20), 59-64. Retrieved from https://link.springer.com/content/pdf/10.2165/00007256-199520020-00001.pdf 
Akcan P. E., Tekgul, N., Karademirci, E., \& Ongel, K. (1999). Adolescence period: Physical growth, psychological and social development process. The Journal of Turkish Family Physician. 3(4), 10-16.

Astrand, P. O. (1977). Health and fitness. New York. Barron's Woodburry.

Bartlett, J. D., Close, G. L., MacLaren, D. P., Gregson, W., Drust, B., \& Morton, J. P. (2011). High-intensity interval running is perceived to be more enjoyable than moderate-intensity continuous exercise: implications for exercise adherence. J Sports Sci., 29(6), 547-53. https://doi.org/10.1080/02640414.2010.545427

Bilgic, M., Pancar, Z., Sahin, F. B., \& Ozdal, M. (2016). Investigation of correlation between two different anaerobic power tests in sedentary children. Gaziantep University Journal of Sport Sciences. 1(2), 40-48. Retrieved from http://dergipark.gov.tr/gaunjss/issue/26868/282545

Borg, G. A. V. (1982). Psychophysical bases of perceived exertion. MedSci Sports Exerc. 14(5), 377-381. https://doi.org/10.1249/00005768-198205000-00012

Castagna, C., Sousa, M., Krustrup, P., \& Kirkendall, D. T. (2018). Recreational team sports: The motivational medicine. Journal of Sport and Health Science. 7(2), 129-131. https://doi.org/10.1016/j.jshs.2017.12.001

Duvivier, B. M., Schaper, N. C., Bremers, M. A., van Crombrugge, G., Menheere, P. P., Kars. M., \& Savelberg, H. H. (2013). Minimal intensity physical activity (standing and walking) of longer duration improves insulin action and plasma lipids more than shorter periods of moderate to vigorous exercise (cycling) in sedentary subjects when energy expenditure is comparable. PLoS One. 9(8), e55542. https://doi.org/10.1371/journal.pone.0055542

Erikoğlu, Ö., Güzel, N.A., Pense, M., \& Örer, G. E. (2015). Comparison of physical fitness parameters with eurofit test battery of male adolescent soccer players and sedentary counterparts. International Journal of Science Culture and Sport. 3(3): 43-52. https://doi.org/10.14486/IntJSCS434

Fredriksen, P. M., Ingjer, F., Nystad, W., \& Thaulow, E. (1998). Aerobic endurance testing of children and adolescents-a comparison of two treadmill-protocols. Scand J MedSci Sports. 8(3), 203-207. https://doi.org/10.1111/j.1600-0838.1998.tb00193.x

Gullu, A. (2011). To describe of performance level in soccer with anaerobic threshold and running velocity by using of a new field test. (Unpublished doctoral dissertation) Gazi University, Ankara, Turkey.

Gullu, A. (2013). The effect of fundamental soccer training on physical and technical skills of sedentary male children. International Journal of Academic Research Part A. 5(5), 86-93. https://doi.org/10.7813/2075-4124.2013/5-5/A.11

Hammami, A., Chamari, K., Slimani, M., Shephard R, J., N Yousfi, N., Tabka, Z., \& Bouhlel1, E. (2016). Effects of recreational soccer on physical fitness and health indices in sedentary healthy and unhealthy subjects. Biol. Sport. 33(2), 127-137. https://doi.org/10.5604/20831862.1198209

Hammami, A., Randers, M. B., Kasmi, S., Razgallah, M., Tabka, Z., Chamari, K., \&Bouhlel, E. (2018). Effects of soccer training on health-related physical fitness measures in male adolescents. Journal of Sport and Health Science. 7(2), 169-175. https://doi.org/10.1016/j.jshs.2017.10.009

Haugen, T. A., Tønnessen, E., \& Seiler, S. (2013). Anaerobic performance testing of professional soccer players 19952010. International Journal of Sports Physiology and Performance. 8(2), 148-156. https://doi.org/10.1123/ijspp.8.2.148

Helge, E. W., Aagaard. P., Jakobsen. M. D., Sundstrup, E., Randers, M. B., Karlsson, M. K., \& Krustrup, P. (2010). Recreational football training decreases risk factors for bone fractures in untrained premenopausal women. Scand $J$ Med Sci Sports. 20(s1), 31-39. https://doi.org/10.1111/j.1600-0838.2010.01107.x

Katis, A., \& Kellis, E. (2009). Effects of small-sided games on physical conditioning and performance in young soccer players. Journal of Sports Science and Medicine. 8(3), 374-380. Retrieved from https://www.ncbi.nlm.nih.gov/pmc/articles/PMC3763282/pdf/jssm-08-374.pdf

Koc, H., \& Aslan, C. S. (2010). The comparison of male handball and volleyball players' selected physical and motor skills. Selcuk University Journal of Physical Education and Sport Science. 12(3), 227-231. Retrieved from https://www.researchgate.net/profile/Cem_Aslan3/publication/290613866

Lee, I. M., \& Skerrett, P. J. (2001). Physical activity and all-cause mortality: what is the dose-response relation? Med Sci Sports Exerc., 33(6), 459-S471. https://doi.org/10.1371/journal.pone.0160876

Lee, W. J., Peng, L. N., Chiou, S. T., \& Chen, L. K. (2016). Relative handgrip strength is a simple indicator of cardio metabolic risk among middle-aged and older people: A nationwide population-based study in Taiwan. PLoS One.11(8), e0160876. https://doi.org/10.1371/journal.pone.0160876 
Lidor, R., \& Ziv, G. (2010). Physical characteristics and physiological attributes of adolescent volleyball players-A Review. Human Kinetics Journals/ Pediatric Exercise Science.; 22(1), 114-134. https://doi.org/10.1123/pes.22.1.114

Mackenzie B (2005). 101 Performance Evaluation Test. Electric Word Plc., (96-117), London. Retrieved from https://38-422-fa15.wiki.uml.edu/file/view/101EvaluationTests.pdf/558074921/101EvaluationTests.pdf

Manshouri, M., Rahnama, N., \& Khorzoghi, M. B. (2014). Effects of pilates exercises on flexibility and volleyball serve skill in female college students. Sport SPA. 11(2), 19-25. Retrieved from https://pdfs.semanticscholar.org/1127/c62b1311d6b5064ed2ac6e9372b5c77ab1bc.pdf

Martinez, D. B. (2017). Consideration for power and capacity in volleyball vertical jump performance. National Strength and Conditioning Association. 39(4), 36-48. https://doi.org/10.1519/SSC.0000000000000297

McKenzie, T. L., Cohen, D. A., Sehgal, A., Williamson, S., \& Golinelli, D. (2006). System for observing play and recreation in communities (SOPARC): Reliability and feasibility measures. Journal of Physical Activity and Health. 3(s1), 208-222. https://doi.org/10.1123/jpah.3.s1.s208

Radu, L. E., Făgăraş, S. P., \& Graurc, C. (2015). Lower limb power in young volleyball players. Procedia-Social and Behavioral Sciences, 191, 1501-1505. https://doi.org/10.1016/j.sbspro.2015.04.371

Rampinini, E., Impellizzeri, F. M., Castagna, C., Abt, G., Chamari, K., Sassi, A., \& Aldo Marcora, S. M. (2007). Factors influencing physiological responses to small-sided soccer games. J Sports Sci., 25(6), 659-666. https://doi.org/10.1080/02640410600811858

Saccol, M. F., Almeida, G. P. L., \& de Souza, V. L. (2016). Anatomical glenohumeral internal rotation deficit and symmetric rotational strength in male and female young beach volleyball players. Journal of Electromyography and Kinesiology. 29, 121-125. https://doi.org/10.1016/j.jelekin.2015.08.003

Sarmento, M. A. (2015). A "Mental health profile" of higher education students. Procedia-Social and Behavioral Sciences. 191, 12-20. https://doi.org/10.1016/j.sbspro.2015.04.606

Sheppard, J. M., Gabbett, T. J., \& Riggs, M. P. (2013). A Volleyball: Physiological testing of elite athletes. (2nd edition) Indoor and Beach Volleyball Players. (475-786) Australian Institute of Sport. Retrieved from https://www.researchgate.net/publication/236888669

Yi D, Khang AR, Lee HW, Son SM, \& Kang YH (2018). Relative handgrip strength as a marker of metabolic syndrome: The Korea National Health and Nutrition Examination Survey (KNHANES) VI (2014-2015). Diabetes Metab Syndr Obes. 11, 227-240. https://doi.org/10.2147/DMSO.S166875

\section{Copyrights}

Copyright for this article is retained by the author(s), with first publication rights granted to the journal.

This is an open-access article distributed under the terms and conditions of the Creative Commons Attribution license which permits unrestricted use, distribution, and reproduction in any medium, provided the original work is properly cited. 